Report

\title{
Breast hamartoma: a case report
}

\author{
Giovanna Gatti ${ }^{1,2,3}$, Giovanni Mazzarol ${ }^{4}$, Serife Simsek ${ }^{1}$, Giuseppe Viale ${ }^{4,5}$, \\ Nicholas Peradze ${ }^{1}$, and Alberto Luini ${ }^{1}$ \\ ${ }^{1}$ Division of Breast Surgery; ${ }^{2}$ Scientific Director's Office, European Institute of Oncology, Milan; ${ }^{3}$ Postgraduate \\ School of General Surgery, University of Perugia; ${ }^{4}$ Division of Pathology, European Institute of Oncology, Milan; \\ ${ }^{5}$ University of Milan, Italy
}

Key words: breast hamartoma, case report, surgery

\section{Summary}

Breast hamartoma is an uncommon benign lesion, composed of varying amounts of fatty, fibrous and glandular elements. It can present as a breast mass and therefore additional care needs to be taken to rule it out in the differential diagnosis of breast carcinoma. We report a case of a breast hamartoma treated at the European Institute of Oncology.

\section{Introduction}

The breast can be affected by different benign lesions which should be ruled out before approaching the patient surgically. Some breast lesions, however, can present diagnostic problems and/or the necessity to be removed due to local aggressiveness or suspicion of malignant progression.

Breast hamartoma is an uncommon benign lesion, composed of varying amounts of fatty, fibrous and glandular elements. On rare occasions carcinoma can arise within hamartomatous masses [1].

We report a case of a breast hamartoma treated at the European Institute of Oncology.

\section{Case report}

A 43-year-old premenopausal woman was referred to our Division of Breast Surgery for a painless lump in her right breast which had been detected by auto-diagnosis.

The patient had three children; she had a history of normal breast feeding after the three pregnancies. At the age of 40 years, she underwent appendicectomy: this was the only surgical report in patient clinical record. Family history was positive for breast cancer (mother affected by breast carcinoma).

On physical examination, the patient presented with a round, mobile mass with a regular shape and smooth margins, $3 \mathrm{~cm}$ diameter, in the upper outer quadrant of the right breast. No lymph nodes were palpable in the right axilla.

Mammographic findings were normal: no sign of disease. The breast ultrasound showed the presence of a right breast mass with oval shape and well-circumscribed margins, and internal heterogeneous echogenicity.
The patient underwent upper outer partial resection in the right breast with the complete removal of a $4.5-\mathrm{cm}$ circumscribed nodule, and had an uneventful postoperative course.

Pathological examination of the specimen revealed a $4.5 \mathrm{~cm}$ circumscribed mass. Microscopically, the mass was defined as breast hamartoma. No foci of malignant cells were detected within the mass.

The patient did not receive any further treatment and was referred for regular follow-up.

\section{Discussion}

Breast hamartomas are uncommon, benign, slow growing lesions of breast: the reported incidence is $0.7 \%$ of benign breast tumours in women [2]. The first report on the topic was by Arrigoni et al. in 1971 [3].

Breast hamartoma is composed of a mixture of glandular fat and fibrous tissue; it is often discovered incidentally during screening mammography. With the increased availability of screening mammography, radiologists are more likely to detect this benign lesion $[1,3,4]$.

Breast hamartoma may present as a discrete painless mass, as was the case with our patient. Clinically concealed as fibroadenoma, it may be difficult to palpate because of its similarity to surrounding normal breast tissue [1].

The diagnosis of breast hamartoma may be related to a genetic defect called Cowden disease. Our patient was not affected by this disease. Cowden disease is an autosomal dominant disorder characterized by multiple hamartomas affecting derivatives of all three germ layers and by an increased risk of breast, thyroid, and endometrial neoplasia. Germline intragenic mutations in 

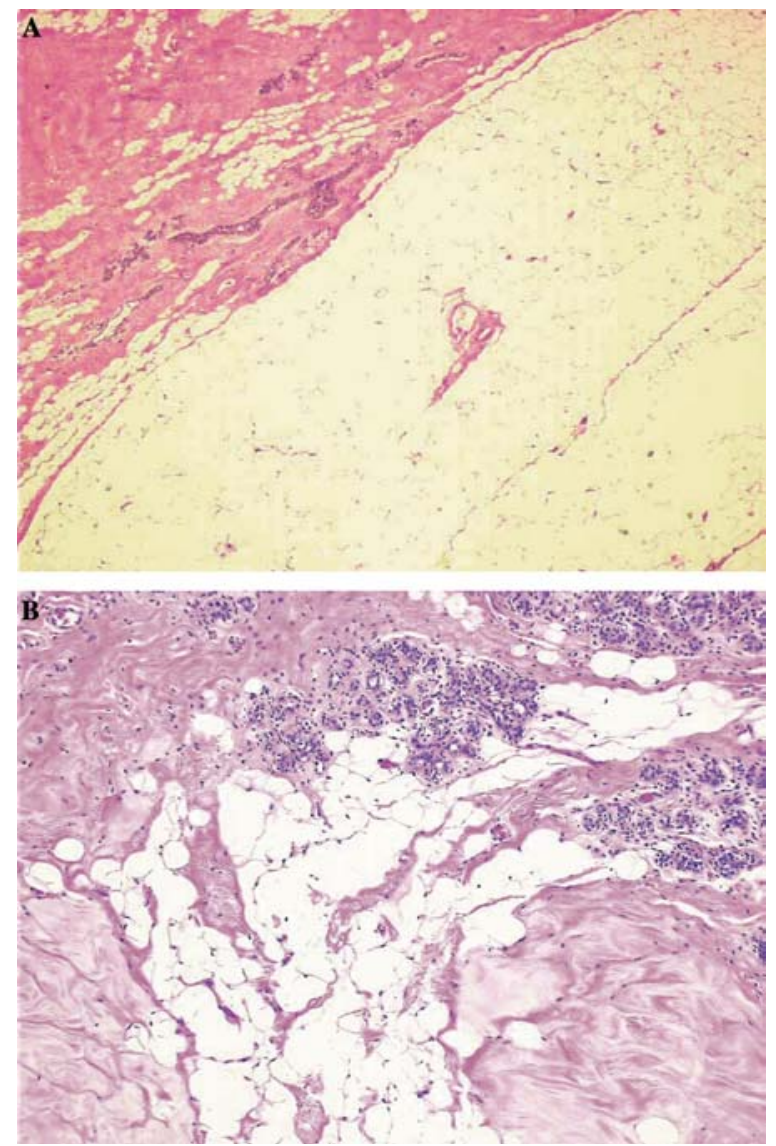

Figure 1. Pathologic findings of the breast hamartoma. A well delimitated breast nodule presents (A) normal lobular and (B) duct structures, mixed with mature fat tissue (H\&E).

PTEN gene are present in $80 \%$ of patients with Cowden syndrome (CS) and in $60 \%$ of patients with BannayanRiley-Ruvalcaba syndrome (BRRS). Finding germline PTEN mutations in patients with BRRS suggests equivalent risks of developing malignancy as in CS with implications for medical management [5-7].

Breast lesions are very common in women with $\mathrm{CD}$. Lesions include fibrocystic disease, which often involves extensive, anatomic abnormalities of the nipple and areola as well as virginal hypertrophy. Approximately $30-50 \%$ of women with $\mathrm{CD}$ develop breast cancer, mainly ductal adenocarcinoma. In patients affected by CD breast carcinoma usually develops at an early age, $<40$ years. In one third of cases, the breast carcinoma is bilateral. Fackenthal et al. recently reported on two cases of breast carcinoma in male patients with $\mathrm{CD}$ [8-11].

Breast hamartoma is commonly described as a rare, benign lesion with a classical mammographic appearance. As already mentioned, Arrigoni et al. introduced the term breast hamartoma and emphasized the encapsulation, macroscopic, and microscopic characteristics of such a lesion. The mammographic diagnosis can be made with a degree of certainty when a circumscribed area consisting of both soft tissue and lipomatous elements is found surrounded by a thin radiolucent zone. Calcifications may develop inside the lesion. The char- acteristic mammographic appearance is a circumscribed mass of mixed fatty and soft tissue elements with a thin pseudocapsule; the ACR BI-RADS category is 2 or 3 .

Ultrasound could play a minimal role in the diagnosis of breast hamartoma in view of the wide sonographic variability; the most common sonographic appearance is, however, a well-circumscribed, solid hypoechoic mass with posterior acoustic shadowing [1].

When a mammographic round mass with a radiolucent halo corresponds to an oval heterogeneous mass surrounded by an echogenic or echolucent circle on a sonogram, hamartoma can in principle be diagnosed. Hamartoma is highly compressible: this characteristic is related to the over-proliferation of matured fat containing normal breast tissues [4].

In the case we are reporting, mammography was not helpful because no alteration was evident, but ultrasonography was diagnostic and the findings were similar to the ones described in the literature.

In general, hamartomas are well-defined masses sharply circumscribed with smooth contours. Histology shows otherwise normal breast and fat tissue distributed in nodular fashion, with a well-defined border, almost compressing the surrounding tissue. Figure 1 shows the pathologic findings in our patient.

Fine needle aspiration (FNAB) can be important for the pathological diagnosis $[12,13]$. Our patient did not undergo FNAB because she nevertheless decided to undergo surgery, due to the distress related to the presence of a breast lump.

Although a clinically palpable small hamartoma does not need excision, it is interesting to note that after surgical removal the breast tissue expands and once again becomes clinically and radiologically symmetrical with a normal appearance. The hamartoma may rarely undergo malignant changes.

\section{References}

1. Baron M, Ladonne JM, Gravier A, Picquenot JM, Berry M: Invasive lobular carcinoma in a breast hamartoma. Breast $\mathbf{J} 9$ : 246-248, 2003

2. Ravakhah K, Javadi N, Simms R: Hamartoma of the breast in a man: a case report. Breast J 7: 266-268, 2001

3. Arrigoni MG, Dockerty MB, Judd ES: The identification and treatment of mammary hamartoma. Surg Gynecol Obstet 133: 577-582, 1971

4. Park SY, Oh KK, Kim EK, Son EJ, Chung WH: Sonographic findings of breast hamartoma: emphasis on compressibility. Yonsei Med J 44: 847-854, 2003

5. Eng C: PTEN: one gene, many syndromes. Hum Mutat 22: 183198, 2003

6. Zhou XP, Waite KA, Pilarski R, Hampel H, Fernandez MJ, Bos C: Germline PTEN promoter mutations and deletions in Cowden/ Bannayan-Riley-Ruvalcaba syndrome result in aberrant PTEN protein and dysregulation of the phosphoinositol-3-kinase/Akt pathway. Am J Hum Genet 73: 404-411, 2003

7. Reifenberger J, Rauch L, Beckmann MW, Megahed M, Ruzicka T, Reifenberger G: Cowden's disease: clinical and molecular genetic findings in a patient with a novel PTEN germline mutation. Br J Dermatol 148: 1040-1046, 2003 
8. Fistarol SK, Anliker MD, Itin PH: Cowden disease or multiple hamartoma syndrome - cutaneous clue to internal malignancy. Eur J Dermatol 12: 411-421, 2002.

9. Schrager CA, Schneider D, Gruener AC, Tsou HC, Peacocke M: Similarities of cutaneous and breast pathology in Cowden's disease. Exp Dermatol 7: 380-390, 1998

10. Schweitzer S, Hogge JP, Grimes M, Bear HD, de Paredes ES Cowden disease: a cutaneous marker for increased risk of breast cancer. Am J Roentgenol 172: 349-351, 1999

11. Schrager CA, Schneider D, Gruener AC, Tsou HC, Peacocke M Clinical and pathological features of breast disease in Cowden's syndrome. An underrecognized syndrome with an increased risk of breast cancer. Hum Pathol 29: 47-53, 1998
12. Gomez-Aracil V, Mayayo E, Azua J, Mayayo R, Azua-Romeo J, Arraiza A: Fine needle aspiration cytology of mammary hamartoma: a review of nine cases with histological correlation. Cytopathology 14:195-200, 2003

13. Herbert M, Schvimer M, Zehavi S, Mendlovic S, Karni T, Pappo I, Sandbank J: Breast hamartoma: fine-needle aspiration cytologic finding. Cancer 99: 255-258, 2003

Address for offprints and correspondence: Dr. Giovanna Gatti, Division of Breast Surgery, European Institute of Oncology, via Ripamonti 435, 20141 Milan, Italy; Tel.: + 39-02-57489215; Fax: + 39-02-57489210; Email: giovanna.gatti@ieo.it 